\title{
Reducing the Risk of Toxic Elements Spreading from Sulphide-Containing Clinkers by Biorecultivation
}

\author{
Olga Saeva ${ }^{1}$, Nataliya Yurkevich $^{1}$, Svetlana Bornikova ${ }^{1}$, Konstantin Cherny $^{2}$, Nikolay Cherny ${ }^{2}$ \\ ${ }^{1}$ IPGG SBRAS, 630090, Novosibirsk, Russia \\ ${ }^{2}$ LLC "Recycling", 652600, Belovo, Russia
}

doi: https://doi.org/10.21467/abstracts.93.82

\begin{abstract}
A B S T RA C T
This paper shows the possibility of biological recultivation on sulphide-containing tailings. The results of experiments on growing perennial herbs, which are well established in cold and moderate belts, on the product of zinc concentrate processing are presented. The object of the study is a waste product of pyrometallurgical processing of zinc concentrate (about 600 thousand tons, Belovo, Kemerovo region, Russia). The main mineral phases are sphalerite, galenite, pyrite, and chalcopyrite. Prior to processing, clinker contained high residual concentrations of a wide range of elements ( $\mathrm{Fe}, \mathrm{Co}, \mathrm{Pb}, \mathrm{Ni}, \mathrm{Cu}, \mathrm{Zn}, \mathrm{Cd}, \mathrm{Be}$ ) in water-soluble forms. The tailings posed a catastrophic threat to the environment being in the city line, due to the formation of drainage solutions contained extremely high amounts of metals, metalloids and dust particles discharge. In 2013, LLC "Recycling" began to recultivate the tailings with preliminary extraction of residual copper and noble metals ( $\mathrm{Au}, \mathrm{Ag}$ ), neutralization of spent clinker with lime and then - creation of an environmentally friendly zone. Clinker neutralization solves the problem of forming acidic highly mineralized drains, and dustdischargecan be stopped by planting perennial plants.

First, the substance of spent clinker and neutralized clinker was studied to assess the reliability of metal binding, and then experiments were carried out on the production territory of LLC "Recycling" to develop a method of recultivation and to determine the possibility of growing herbs on the obtained substrate. Important changes in the composition of water-soluble forms of elements are determined with respect to metals (Fe, Mn, Al, Cu, Zn, Cd, Co, Ni): their concentrations in aqueous extracts from neutralized clinker decreased radically by more than 3 orders. However, it should be noted that As and Se appeared in the neutralized clinker extracts at rather high concentrations of 0.085 to $0.11 \mathrm{mg} / \mathrm{L}$ (As) and 0.071 to 0.061 $\mathrm{mg} / \mathrm{L}(\mathrm{Se})$. These metalloid elements, unlike metals, remain (or become) mobile in neutral - subalkali waters. In general, the results prove the high efficiency of the applied technology to reduce metal mobility and the possibility of moving to the next stage. In order to find out the optimal conditions of biorecultivation, natural experiments were carried out to plant the substrate with grass in different clinker/soil ratios. Two beds measuring $4 \times 1 \mathrm{~m}^{2}$ were made, in one of them the base was the substance of spent clinker, on which a layer of soil of $20 \mathrm{~cm}$ was applied, the second was background and consisted only of soil. The bed which basis was a clinker substance was are divided into four parts: on the first the grass was sowed directly to the soil (1.1, fig. 1), on the second the soil was mixed with clinker in the ratio the clinker/soil =1/3 (1.2, fig. 1), on the third $-2 / 3$ (1.3, fig. 1), on the fourth - 1/1 (1.4 fig. 1). Samples of prepared substrate were taken on each division, soil and clinker samples were taken. Samples were analyzed for total content of elements, water extracts were made from them and concentration of movable shapes of elements was determined. In the experiment for sowing, a mixture of multiple herbs "GNOM" was used (oatmeal red Festucarubra - 60\%, raigras grazing Loliumperenne L. - 15\%, oatmeal sheep Festucaovina - 10\%, mint Poapraténsis - 15\%). After seeding for 2 weeks beds were watered, then watering was carried out naturally, with rainwater. During the vegetative season there was observation of plant growth, documentation of their average length. At the end (C) 2020 Copyright held by the author(s). Published by AIJR Publisher in "Abstracts of The Second Eurasian RISK-2020 Conference and Symposium” April 12- 19, 2020, Tbilisi, Georgia. Jointly organized by AMIR Technical Services LLC, Georgian Technical University, Institute of Geography (Kazakhstan) and Russian Institute of Petroleum Geology and Geophysics.

AijR DOI: $10.21467 /$ abstracts. 93
\end{abstract}


The Second Eurasian RISK-2020 Conference and Symposium

of summer the grass was cut, from each division separately, weighed and analyzed. As a result, quantitative estimates were obtained on the intensity of plant growth on a substrate of different composition and recommendations were made on the optimal scheme of neutralization of spent clinker and recultivation of the territory.

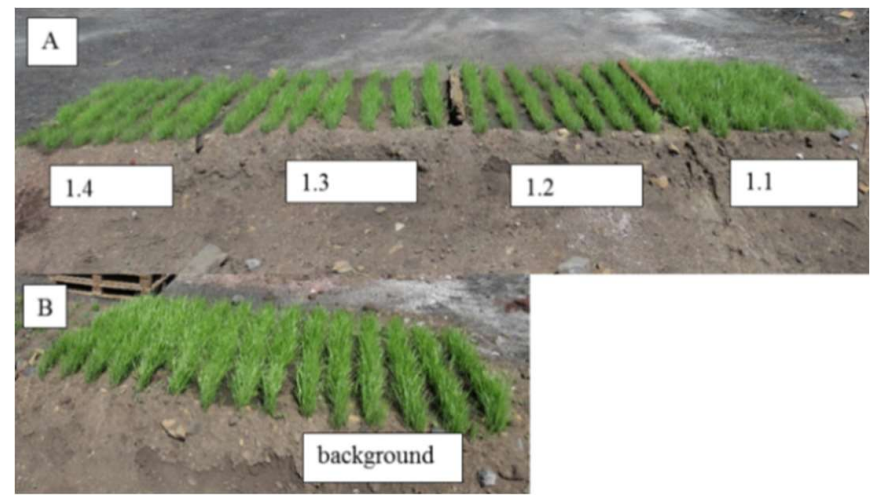

Figure 1. Seedlings 1.5 months after sowing: A - experimental bed; B - background bed.

According to the results of the analysis of ISP-MS in the composition of water extracts from the material of beds, the metal concentrations did not exceed the clark values for the hydrosphere. The exception was copper (excess over clark on different lines by 6 - 30 times) and metalloids: As (by 6 - 20 times), Sb (by 2 20 times), Se (by 6 - 70 times). The $\mathrm{pH}$ and the conductivity of the aqueous extracts from 1 to 4 of the site increases because the neutralized alkaline clinker ( $\mathrm{pH}$ about 12, Fig.2), but when mixed with soils, neutral values are achieved (site 1.2 and 1.3).

The difference in plant growth on four sites was visible and confirmed after measurement and weighing of cut grass. The average height of sprouts decreases along the bed from 10 to $6 \mathrm{~cm}$, on the background section the grass height was $12 \mathrm{~cm}$ (Fig. 2).
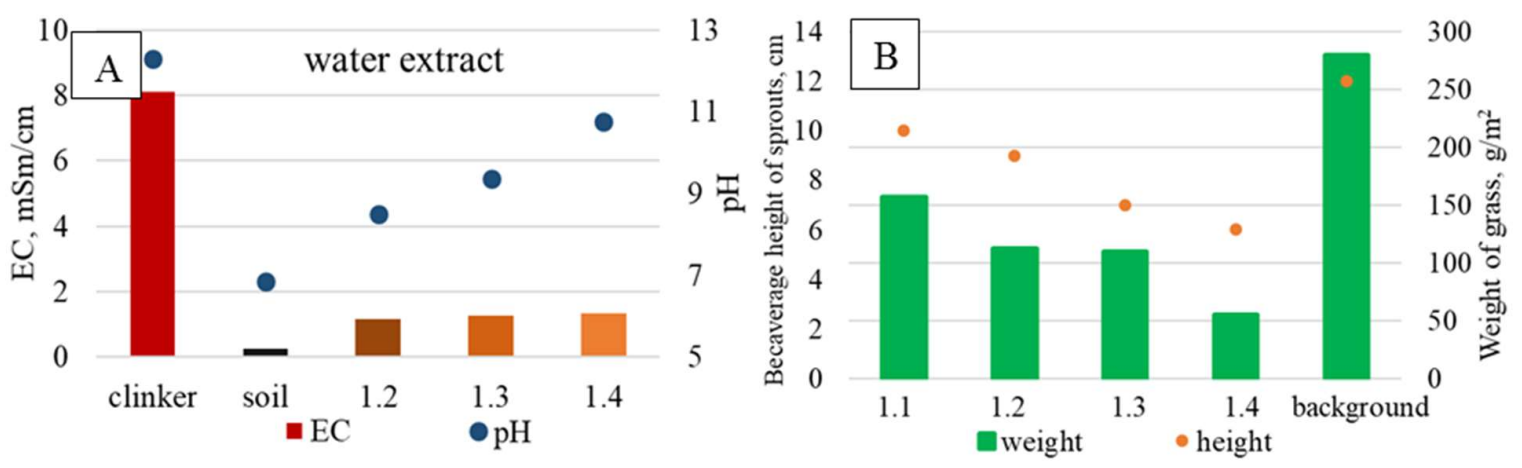

Figure 2.A - pH and electrical conductivity (EC) of water extracts from bed substance, clinker and soil. B -

Height and weight of beveled grass.

During the experiments, the optimal clinker/soil ratio was selected for planning the territory with salted traumas - not more than $2 / 3$, with the ratio of $1 / 1$ plants markedly suppressed and their growth suppressed. This is due to the aggressive environment: the addition of lime leads to an increase in $\mathrm{pH}$ values to the level of the strongly alkaline environment, which has a main impact on the germination and further growth of herbs. Above-ground parts of plants do not accumulate dangerous concentrations of elements, therefore this trauma mixture can be effectively used for recultivation works.

Funding. This research was funded by the Russian Science Foyndation, grant number 19-17-00134. 